\title{
Differences in the physical demands between handball and beach handball players
}

\section{Diferenças nas exigências físicas entre jogadores de handebol e handebol de praia}

\author{
David Mancha-Triguero ${ }^{1}$ \\ (D) https://orcid.org/0000-0001-8080-7565 \\ Sergio González-Espinosa ${ }^{1}$ \\ (D) https://orcid.org/0000-0003-0787-5136 \\ Luis G. Córdoba² \\ (D) https://orcid.org/0000-0002-7042-2626 \\ Javier García-Rubio ${ }^{1}$ \\ (D) https://orcid.org/0000-0001-6426-0002 \\ Sebastián Feu² \\ (D) https://orcid.org/0000-0003-2959-5960
}

Abstract - Handball is one of the most practiced team sports worldwide that consists of different modalities, with the aim of reaching as many users as possible. One of the modalities with increasing interest in the last years is Beach Handball, as it takes the advantage of the absence of competitive calendar in the standardized modality so that users continue practicing. A comparative analysis was performed between standard handball (indoor) and beach handball athletes in order to determine the demands of both modalities and determine if they are similar. The competition was evaluated by analyzing external load variables: number of steps, jumps, impacts and Player load. The selected sample was composed of U-16 players from both modalities. Each player was equipped with WIMU ${ }^{\mathrm{TM}}$ inertial device. The results showed that the standard modality requires greater physical demands than the beach modality. For this reason, the physical demands of the different modalities require different training processes to obtain the best possible results in the competition.

Key words: Athlete; Intensity; Load; Physiology.

Resumo - O handebol é um dos esportes coletivos mais praticados em todo o mundo, que consiste em diferentes modalidades, com o objetivo de atingir o maior número possivel de usuários. Uma das modalidades em expansão nos últimos anos é o Handebol de Praia, pois aproveita a ausência de calendário competitivo na modalidade padronizada para que os usuários continuem praticando. Uma análise comparativa foi realizada entre atletas de handebol padronizado (na pista) e handebol de praia, a fim de determinar as demandas de ambas as modalidades e determinar se essas demandas são semelhantes. A competição foi avaliada através da análise das variáveis externas de carga: número de etapas, saltos, impactos e Player Load. A mostra selecionada foram jogadores de ambas as disciplinas na categoria cadete. Cada jogador foi equipado com um dispositivo inercial WIMUTM. Os resultados mostraram que a modalidade padronizada exige dos atletas maior demanda física que a modalidade de praia. Por esse motivo, os requisitos físicos de ambas as modalidades exigem diferentes processos de treinamento para obter os melhores resultados possiveis na competição.

Palavras-chave: Atleta; Intensidade; Carga; Fisiologia.
1 Training Optimization and Sport Performance Research Group (GOERD). Faculty of Sport Sciences. University of Extremadura. Cáceres. Spain.

2 Training Optimization and Sport Performance Research Group (GOERD). University of Extremadura. Badajoz. Spain.

Received: January 16, 2020 Accepted: September 09, 2020

\section{How to cite this article} Mancha-Triguero D, González-Espinosa S, Córdoba LG, García-Rubio J, Feu S. Differences in the physical demands between handball and beach handball players. Rev Bras Cineantropom Desempenho Hum 2020, 22:e72114. DOl: http://dx.doi.org/10.1590/19800037.2020v22e72114

Copyright: This work is licensed under a Creative Commons Attribution 4.0 International License. 


\section{INTRODUCTION}

Handball is classified as collaboration-opposition sport or invasion sport ${ }^{1}$. In addition, handball is characterized by being a contact team sport that has intermittent tasks interspersed with continuous activities, such as walking and running in response to different offensive and defensive situations ${ }^{2}$.

Handball is categorized as a hybrid sport, since, during practice, there are moments in which actions require aerobic metabolism and moments that require anaerobic metabolism ${ }^{3}$, with great amount and variety in movements, ball manipulations and interaction with other players.

Handball is constantly evolving, demanding greater physiological adaptations and specific morphological characteristics from athletes ${ }^{4}$. These evolutions sometimes affect the creation and enhancement of other variants of the sport. In this case, as an evolution to conventional handball, beach handball has been developed and promoted in recent years.

These evolutions cause not only adaptations in the physiological component of athletes, but also modifications in the formal or regulatory aspects of the sport with the aim of making it novel, fun and easily reproducible.

In this case, beach handball emerged as an evolution of handball as a recreational sport ${ }^{5}$, in which athletes promote competitions and practices in the summer months. At present, this sporting modality is booming and there are numerous competitions and clubs promoting handball training.

For all these reasons, as sports are in continuous evolution, the analysis of the competitive load is of vital importance since, if it is quantified through reliable and objective methods, both the requirements and demands generated by the sport on the athlete will be known, which information can be used to adapt, design and plan training, since adaptation of sport tasks is not the correct method (For example: adapting $5 \times 5$ tasks in basketball to the $3 \times 3$ play).

In this line, the quantification of the competition should be relevant information to be taken into account by coaches or physical trainers, because the current trend of training in team sports is based on the reproduction of the specific performance of the competition in a non-competitive context ${ }^{6}$.

For this, it is necessary to carry out a thorough review of the competition characteristics that gathers the information necessary to design and plan an appropriate and effective training program ${ }^{7}$. The collection of data on the athlete's demands (external load) and requirements (internal load) during a competition is essential, since it provides relevant information about the athlete ${ }^{8}$ and, consequently, about the result ${ }^{9}$.

The load quantification is defined as the total sum of stimuli to which the player is submitted during the preparation or training process ${ }^{10}$. This load quantification becomes one of the main responsibilities of the physical trainer, as it can make the difference between a team that is prepared to compete optimally and a team that is not ${ }^{11}$. This quantification can be organized according to different variables and available material. One of the most studied variables in Sports Science is the distance traveled by 
players during matches. This information can be useful both to improve the inherent physical actions of players during training and to assess physical condition during competition ${ }^{12}$. Many authors combine this variable with heart rate (HR) responses and muscle energy sources to assess the physiological demands of team sports ${ }^{13}$. This knowledge allows coaches to plan effective training programs and reduce the fatigue and stress rate in the musculoskeletal systems of their athletes ${ }^{14}$.

The analysis of competitive activity is of special importance in handball. After analyzing various championships, it was observed that training has to be adapted to the requirements of the competition ${ }^{15}$ and to evolve as the game changes ${ }^{16}$. This analysis of competitive activity can be carried out through direct and indirect methods, including different instruments such as subjective scales, analysis of internal load, external load or through the load quantification with the help of inertial devices whose final objective is to know the physical requirements of the sport in a reliable and real way. For this, the training or competition load is analyzed. Among the competition analysis methods, one of the most used is the direct observation, as it is an analysis model that helps to better perceive and study the relationships that occur within a sports game ${ }^{17}$. Some authors do not consider it the most appropriate, since it has an important subjectivity component ${ }^{18}$. It can also be analyzed through instruments for video analysis ${ }^{19}$. In this context, the use of microtechnology is on the rise through inertial devices that provide real and objective information about the athlete ${ }^{20}$.

As far as we know, the samples that have been analyzed so far have been composed of professional or amateur teams ${ }^{21}$, and using video analysis as resource ${ }^{19}$. Therefore, it could be concluded that there are no works comparing the physiological demands and the competitive load between handball and beach handball athletes in the training category. The following objectives are proposed for this research: i) To describe the physiological demands and the competitive load of beach handball; ii) To carry out a comparative analysis between handball and beach handball in order to know if the physiological demands and the competitive load are similar; iii) To confirm if it is possible to make generalizations regarding the competitive load in handball or otherwise, if they are different sports and require different training processes.

\section{METHOD}

\section{Design}

This research is positioned within studies of comparative associative strategy, based on a cross-sectional design through the design of natural group ${ }^{22}$ in order to characterize the performance of handball players through the competition-type analysis (Handball or Beach Handball).

\section{Sample}

The study was carried out from the analysis of two different championships. 
On the one hand, for handball, the final male U-16 (with average age of 15.4 years \pm 0.3 ) of the $2016 / 2017$ handball championship was analyzed ( $\mathrm{n}$ $=19$ ). On the other hand, all matches that were held in the U-16 category (with mean age of 15.6 years \pm 0.3 ) of an interregional beach handball championship $(\mathrm{n}=168)$ were analyzed.

\section{Material and instruments}

All players of both modalities were equipped with the same material to quantify competitive load. The internal load was analyzed using Garmin ${ }^{\circledR}$ heart rate monitor to determine heart rate, while to record the athlete's external load, Wimu ${ }^{\circledR}$ inertial device was used, which allows monitoring physical activity and movement with the objective of knowing the competitive load of athletes. The SPro ${ }^{\circledR}$ software was used to analyze all information collected by the inertial device. Regarding the placement of the inertial device, in team sports, it is placed between the scapulae as recommended by the manufacturer and because it is the optimal location for the quality of data collection. Both the inertial device and the computer software were obtained from company RealTrack Systems (Almería, Spain).

\section{Variables}

Independent variable was the sport modality (Handball and Beach Handball, hereinafter $\mathrm{BH}$ ). The rest of variables that were defined were 7: i) Mean Heart Rate (HRMean); ii) Maximum Heart Rate (HRMax); iii) Percentage of Maximum Heart Rate (\% HRMax); iv) Time that the athlete is above $85 \%$ the Maximum Heart Rate ( $\geq 85$ HRMax); v) Steps; vi) Jumps; vii) Player Load (PL).

The variables mentioned above are grouped according to their origin in Internal Load Variables and External Load Variables. Internal Load Variables: i) Mean Heart Rate: established with the arithmetic mean of the number of beats per minute (bpm) in a specific period of time (a training task or the playing time in a match); ii) Maximum Heart Rate: the arithmetic mean of the maximum number of beats per minute (bpm); iii)\% Maximum heart rate: percentage of maximum heart rate at which each athlete is working; iv) Time that the athlete is above $85 \%$ of the Maximum Heart Rate: Using the Maximum Heart Rate during the competition, the total time in which the athlete is above that percentage is quantified because the activities above that range are classified as high-intensity activities. External Load Variables: i) Steps: movement that implies advance with standard elevation of less than $400 \mathrm{~ms}$ of flight measured through the device accelerometry; ii) Jumps: movement that consists of rising from the track with standard impulse that implies more than $400 \mathrm{~ms}$ of flight to fall on the same place or on another measured through the device accelerometry; iii) Player Load: It is a vector magnitude derived from triaxial accelerometry data that quantifies movement at high resolution. Accelerations and decelerations are used to construct a cumulative measure of the change rate in acceleration. Cumulative measure (PL) and intensity measure (PL. 
$\min ^{-1}$ ) are used, thus being able to indicate the stress rate to which the player is submitted during a determined period of time. Moderate-high degree of reliability and validity is the load unit ${ }^{20}$. The last three variables (steps, jumps and Player Load) were normalized to the number of actions per minute, since all players did not spend the same time on the track.

\section{Statistic analysis}

First, descriptive analysis was performed to obtain information on each variable (Mean and Standard Deviation). Once the first step had been carried out, exploratory analysis was performed using the criteria assumption tests ${ }^{23}$. The Assumption of Normality (Kolmogorov-Smirnov Test), Assumption of Homoscedasticity (Levene's Test), and Assumption of Randomization (Runs Trimming Test) were tested to establish a comparison of the appropriate hypothesis model ${ }^{24}$. Subsequently, taking into account the results in previous tests, the $T$ test for independent samples was carried out in order to compare variables according to the sport modality. Finally, the Effect Size was quantified using Cohen's d, being classified as low effect (0-0.2), small effect (0.2-0.6), moderate effect (0.6-1.2), large effect $(1.2-2.0)$ and very large effect $(>2.0)^{25}$. The software used for the analysis was SPSS version 21.0. The significance value was established at $\mathrm{p}<.05^{26}$.

\section{Procedure}

First, players and coaches were informed about the research protocol, requirements, benefits and risks. Data collection of this research was first agreed with the Autonomous Federation in charge of the competition, being approved by the ethics committee of the local University (No. 67/2017). In addition, informed consent was obtained before the start of the study from both teams and Federation. After explaining the protocol to players and coaches, a familiarization phase was carried out during a training session with participants of teams participating in the study. The purpose of these training sessions was for players to adapt to the protocol of action and the material with which they would be equipped. The recording of the competition was carried out in two different processes and environments: on the one hand, the final of the regional championship in the men's handball U-16 category was recorded; on the other hand, the $\mathrm{BH}$ interregional championship was registered. For the competition analysis, warm-up periods, rest intervals, exclusions and time-outs were excluded. Players who were on the court were exclusively analyzed in order not to contaminate the sample with players who were not playing. All matches analyzed had the presence of goalkeepers, who were not analyzed.

\section{RESULTS}

The results obtained in this investigation are shown below. Table 1 shows the descriptive results, as well as inferential analysis to find out if there are differences in physical demands between sports modalities. 
Table 1. Descriptive results, inferential analysis and Effect Size of variables analyzed according to the sport modality.

\begin{tabular}{|c|c|c|c|c|c|c|c|}
\hline & \multicolumn{2}{|c|}{ Handball } & \multicolumn{2}{|c|}{ Beach Handball } & \multirow[b]{2}{*}{ sig. } & & \multirow[b]{2}{*}{ Effect Size } \\
\hline & Mean & SD & Mean & SD & & & \\
\hline Acc & 3204 & 942.04 & 530.7 & 307.60 & .000 & * & 3.973 \\
\hline Decel & 3201.42 & 942.93 & 532.8 & 308.80 & .000 & * & 3.961 \\
\hline Acc/min & 30.78 & 6.59 & 17.52 & 7.13 & .116 & & 1.923 \\
\hline Decel/min & 30.75 & 6.60 & 17.58 & 7.17 & .122 & & 1.904 \\
\hline Steps /min & 37.61 & 12.43 & 27.64 & 8.91 & .000 & * & 0.936 \\
\hline Jumps/min & 0.55 & 0.37 & 0.16 & 0.095 & .000 & * & 1.483 \\
\hline Total Impacts & 2113.78 & 1569.77 & 475.6 & 191.61 & .000 & * & 1.539 \\
\hline Impacts $0-5 \mathrm{G}$ & 1445.52 & 901.40 & 333.85 & 130.28 & .000 & * & 1.812 \\
\hline Impacts 5-8G & 526.15 & 471.72 & 117.2 & 59.95 & .000 & * & 1.277 \\
\hline Impacts $>8 G$ & 142.10 & 258.19 & 24.55 & 13.02 & .000 & * & 0.676 \\
\hline Impacts $0-5 \mathrm{G} / \mathrm{min}$ & 13.18 & 7.69 & 6.35 & 2.55 & .000 & * & 1.24 \\
\hline Impacts $5-8 \mathrm{G} / \mathrm{min}$ & 4.73 & 4.12 & 2.23 & 1.19 & .000 & * & 0.858 \\
\hline $\begin{array}{l}\text { Impacts >8G/min } \\
\mathrm{PL} / \mathrm{min}\end{array}$ & $\begin{array}{l}1.26 \\
0.82\end{array}$ & $\begin{array}{l}2.29 \\
0.27\end{array}$ & $\begin{array}{l}0.46 \\
0.58\end{array}$ & $\begin{array}{l}0.24 \\
0.16\end{array}$ & $\begin{array}{l}.000 \\
.032\end{array}$ & * & $\begin{array}{l}0.514 \\
1.112\end{array}$ \\
\hline
\end{tabular}

Note. Acc: Accelerations; Decel: Decelerations; Acc / min: Accelerations per minute; Decel / min: Decelerations per minute; Impacts 0-5G: Impacts received with force between 0 and 5G; Impacts 5-8G: Impacts received with force between 5 and 8G; Impacts> 8G: Impacts received greater than $8 \mathrm{G}$; Impacts $0-5 \mathrm{G} / \mathrm{min}$ : Impacts received with force between 0 and $5 \mathrm{G}$ per minute; Impacts 5-8G / min: Impacts received with force between 5 and $8 \mathrm{G}$ per minute; Impacts $>8 \mathrm{G} / \mathrm{min}$ : Impacts received greater than $8 \mathrm{G}$ per minute; $\mathrm{PL} / \mathrm{min}$ : Player Load per minute; P-value $=.05$

Table 1 shows differences between sports modalities, with Handball being physically more demanding than $\mathrm{BH}$. Values, both in absolute terms and in values relativized per minute, in Handball are higher. Regarding the Effect Size, it was observed that one variable had small effect, four variables had moderate effect, seven variables had large effect and two variables very large effect.

\section{DISCUSSION}

The aims of this work were to know the physical-physiological demands and the competitive load of both sports modalities and to carry out a comparative analysis in order to be able to determine if it can be generalized in handball in terms of the demands regardless of the modality (in this work between Handball and $\mathrm{BH}$ ).

The analysis of the external load of handball matches in different modalities in order to compare the demands is not a common practice today. There are few references on works with the same theme, with the vast majority being studies related to the analysis of the standard modality in high-level teams or national teams ${ }^{19}$ or to beach handball championships in the elite-level amateur category ${ }^{26,27}$.

Regarding the results obtained, significant differences were found in most of variables analyzed. On the one hand, neuromuscular variables such as accelerations and decelerations show differences both in absolute values and in values relativized per minute. In this context, values similar to those obtained in this research are shown in previous studies in a sample similar to that analyzed in this research ${ }^{28}$. On the other hand, in the $\mathrm{BH}$ modality, the results related to accelerations and decelerations are lower than values 
found in the Handball modality ${ }^{27}$. These differences in absolute results were also affected by the match duration, being 60 minutes in Handball and 20 minutes in $\mathrm{BH}$. For this reason, in values relativized per minute, the difference is significant, and may be mainly due to the size of the playing field, since the Handball court is greater than twice the playing space of $\mathrm{BH}$. Regarding the playing surface, Handball has hard and stable surface, which is easier to make changes in speed or direction than in $\mathrm{BH}$.

Regarding variables jumps and steps relativized per minute, in the Handball modality, results are higher than in $\mathrm{BH}$. Thus, the distance covered in a handball match is between 60 and $80 \mathrm{~m}$ per minute depending on the level and gender of the sample ${ }^{29}$. However, in $\mathrm{BH}$, the distance covered during a match is between 59 meters/minute and 69 meters/minute depending on the gender and category of the sample ${ }^{27}$. These differences are mainly due to the size of the playing field, since in a sport such as handball in which attack and defense phases alternate, movements are of greater distance in Handball than in $\mathrm{BH}$ because the alternation of attack and defense phases is linked to the continuous change of players. In addition, Handball is a high-intensity intermittent sport in which most actions end with a jump ${ }^{2}$ (throw). For this reason, in Handball, the number of jumps is greater, since in most cases, throws are made to surpass the defense or to throw the ball from a closer distance, while in the $\mathrm{BH}$ modality, the game always creates a situation of superiority, since the goalkeeper of the attacking team participates in the attack phase, creating an advantage over the defense and the jump movement is not so necessary.

On the other hand, regarding the variables of total impacts and ratios as a function of the $\mathrm{G}$ forces, all variables had significant differences between modalities. The results show that the Handball modality obtains higher results in the $\mathrm{G}$-forces that players support and in the total number of impacts received than in the $\mathrm{BH}$ modality. Thus, the results confirm that the number of high-intensity impacts $(>5 \mathrm{G})$ received by a player during the Handball competition is around $97^{30}$, while in $\mathrm{BH}$, the number of impacts is $78.4^{27}$. These differences are due to the playing surface, since in $\mathrm{BH}$, the sand reduces the intensity of received impacts because it is a soft surface and softens the aggressiveness of falls. These differences are related to a lower injury index, since, in most cases, these $\mathrm{G}$-forces are produced in eccentric contractions, which cause greater load or muscle fatigue.

Finally, in variable Player Load relativized per minute, there are differences between sport modalities. This variable is related to all variables mentioned above, since it is the result of the analysis of forces and accelerations suffered by the athlete in the 3 axes. Regarding the Handball modality, the Player Load supported by an athlete during the competition is similar to that found in this research ${ }^{28}$, while, in the $\mathrm{BH}$ modality, the Player Load supported by an athlete is greater than one unit per minute ${ }^{27}$. These differences are mainly due to the size of the playing field, the surface and the number of players. Related to the latter, in Handball, the size that corresponds to each athlete is 57 meters $^{2}(6 \times 6)$, excluding the goalkeeper's 
area, while, in the $\mathrm{BH}$ modality, the area that belongs to each athlete is around 26 meters $^{2}(4 \times 3)$, excluding the goalkeeper's area (Figure 1).

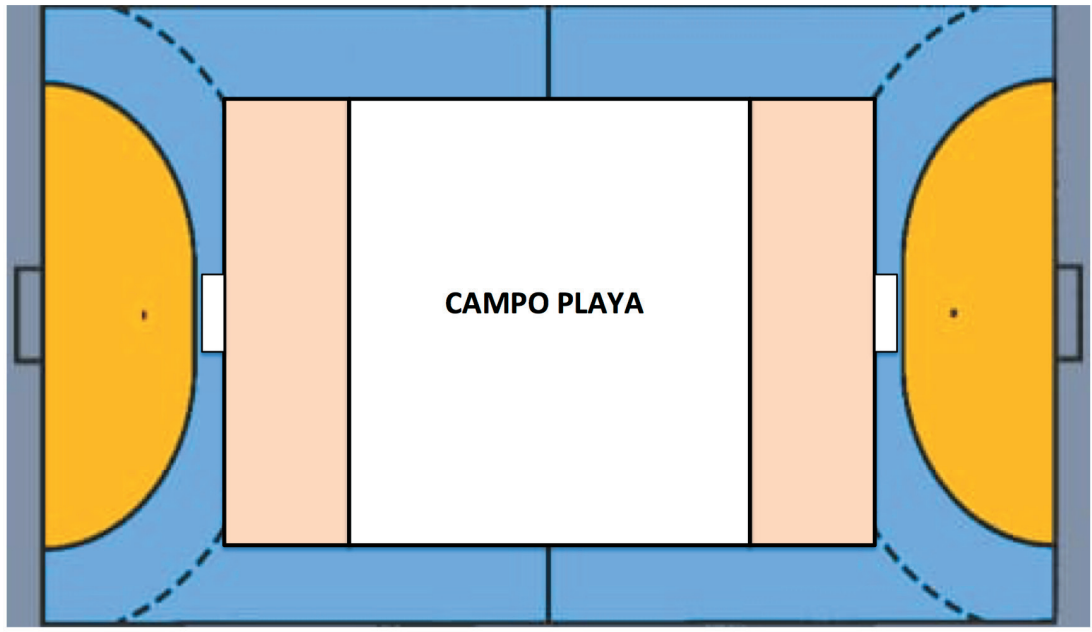

Figure 1. Graphic representation of the field sizes of handball and beach handball.

\section{CONCLUSION}

The analysis of the competitive load in sport through microtechnology is a valid and reliable method to assess the demands of each sport modality. In this research, the analysis of different handball modalities was carried out. Therefore, it could be concluded that Handball and BH are different sports, with different demands, which must be trained differently in order to optimize results. In addition, on this occasion, it was shown that Handball is physically more demanding than $\mathrm{BH}$ due to the size of the playing field, the surface and the number of players, and $\mathrm{BH}$ could be a good alternative to start in Handball. In the future, this research line will be rarely used and it would be interesting to expand the sample analyzed, both in matches and in players.

\section{Acknowledgments}

This work has been partially subsidized by Research Groups (GR18170) of the "Junta de Extremadura" (Ministry of Economy and Infrastructure), with the contribution of the European Union through the FEDER.

\section{COMPLIANCE WITH ETHICAL STANDARDS}

\section{Funding}

This research has been partially subsidized by Research Groups (GR18170) from Junta de Extremadura (Consejería de Economía and Infraestructuras); with the contribution of the European Union through FEDER and for the financial aid for pre-doctoral students granted by the University of Extremadura through its Own Research Plan. 


\section{Ethical approval}

Ethical approval was obtained from the local Human Research Ethics Committee-University of Extremadura and protocol (No. 233/2019) was written in accordance with standards set by the Declaration of Helsinki.

\section{Conflict of interest statement}

The authors have no conflict of interests to declare.

\section{Author Contributions}

Conceived and designed the experiments: JG-R and SF. Performed experiments: DM-T and SG-E. Analyzed data: LGC. Contributed with reagents/materials/analysis tools: JG-R, SF and LGC. Wrote the paper: DM-T and SG-E.

\section{REFERENCES}

1. Mitchell SA, Oslin JL, Griffin LL. Sport foundations for elementary physical education: A tactical games approach. Champaign: Human Kinetic; 2003.

2. Hasan AA, Reilly T, Cable NT, Ramadan J. Anthropometric profiles of elite Asian female handball players. J Sports Med Phys Fit 2007; 47(2): 197-202.

3. Souhail H, Castagna C, Mohamed H, Younes H, Chamari K. Direct validity of the yo-yo intermittent recovery test in young team handball players. J Strength Cond Res 2010; 24(2): 465-470.

4. Vargas RP, Dick DD, Santi H, Duarte M, Cunha AT. Evaluación de características fisiológicas de atletas de balonmano femenino. Fitness Performance 2008; 7(2): 93-98.

5. Morillo-Baro JP, Reigal RE, Hernández-Mendo A. Análisis del ataque posicional de balonmano playa masculino y femenino mediante coordenadas polares. Rev Int Cienc Deporte 2015; 11(41): 226-224.

6. Ford PR, Yates I, Williams AM. An analysis of practice activities and instructional behaviours used by youth soccer coaches during practice: exploring the link between science and application. J Sports Sci 2010; 28(5): 483-495.

7. Barbero-Álvarez JC, Castagna C. Activity patterns in professional futsal players using global position tracking system. J Sport Sci Med 2007; 6: 208-209.

8. Drust B, Atkinson G, Reilly T. Future perspectives in the evaluation of the physiological demands of soccer. Sports Med 2007;37(9): 783-805.

9. Antúnez A, García-Rubio J, Sáez-Blázquez FJ, Valle A, García-Martín A. Diferencias en los indicadores de rendimiento entre los equipos ganadores y perdedores en etapas de formación en balonmano en función del género y la diferencia final de goles. E-balonmano Rev Cienc Deporte 2013, 9(1): 5-16.

10. Coque I. Valoración subjetiva de la carga del entrenamiento técnico- táctico. Una aplicación práctica (I). Clinic 2008;81: 39-43.

11. Barbero-Álvarez JC, Gómez-López M, Barbero-Álvarez V, Granda J, Castagna C. Heart rate and activity profile for young female soccer players. J Hum Sport Exerc 2008; 3(2): 1-11.

12. Barros RML, Misuta MS, Menezes RP, Figueroa PJ, Moura FA, Cunha SA, et al. Analysis of the distance covered by the first division Brazilian soccer players obtained with an automatic tracking method. J Sport Sci Med 2007; 6: 233-242.

13. Krustrup P, Mohr M, Steenberg A. Muscle and blood metabolites during a soccer game: Implications for sprint performance. Med Sci Sports Exerc 2006;38: 1165-1174.

14. McKeag DB. Basketball. Indianapolis: Blackwell Science. 2003 
15. Sevim Y, Bilge M. The Comparison of the Last Olympic, World and European Men Handball Championships and the Current Developments in World Handball. Res Yearbook 2007;13(1): 65-72.

16. Mavridis G, Tsamourtzis E, Michaltsi M. Analysis of the technical-tactical elements in junior team handball using video recordings and a special software. Leistungssport 2006; 36(5): 39-42

17. Silva A, Sánchez F, Garganta J, Anguera MT. Patrones de juego en el fútbol de alto rendimiento. Análisis secuencial del proceso ofensivo en el campeonato del mundo Corea-Japón 2002. Cult Cienc Deporte 2005; 1 (2): 65-72.

18. Sampaio J, Ibáñez SJ, Feu S. Discriminative power of basketball game-related statistics by level of competition and sex. Percept Mot Ski 2004;99: 1231-1238.

19. Belka J, Hulka K, Safar M, Weisser R, Samcova A. Analyses of time-motion and heart rate in elite female players (U19) during competitive handball matches. Kinesiology 2014; 46(1): 33-43.

20. Barreira P, Robinson MA, Drust B, Nedergaard N, Raja Azidin RMF, Vanrenterghem J. Mechanical Player Load ${ }^{\mathrm{TM}}$ using trunk-mounted accelerometry in football: Is it a reliable, task-and player-specific observation? J Sport Sci 2016; 35(17): 1-8.

21. Karcher C, Buchheit M. On-court demands of elite handball, with special reference to playing positions. Sport Med 2014;44(6): 797-814.

22. Ato M, López JJ, Benavente A. Un sistema de clasificación de los diseños de investigación en psicología. Anal Psico 2013;29(3): 1038-1059.

23. Cubo S. La investigación experimental. En: Cubo S; Marín B, Ramos JL, organizadores. Métodos de investigación y análisis de datos en ciencias sociales y de la salud. Madrid: Ed. Pirámide; 2011. p.235-326

24. Field, A. (2009). Discovering statistics using SPSS. Third Edition. Londres: SAGE.

25. Hopkins W, Marshall S, Batterham A, Hanin J. Progressive statistics for studies in sports medicine and exercise science. Med Sci Sports Exerc 2009;41(1): 3-12.

26. Pardo A, Ruiz MA. SPSS 11. Guía para el análisis de datos. Madrid: Mc Graw Hill. 2002

27. Pueo B, Jiménez-Olmedo JM, Penichet-Tomas A, Becerra MO, Agullo, JJE (2017). Analysis of time-motion and heart rate in elite male and female beach handball. J Sports Sci Med 2017;16(4): 450-458.

28. Mancha-Triguero D, Reina M, Baquero B, García-Rubio J, Ibáñez SJ. Análisis de carga competitiva en jugadores de balonmano de formación en función del resultado final. E-Balonmano Rev Cienc Deporte 2018;14(2): 99-108.

29. Šibila M, Vuleta D, Pori P. Position-related differences in volume and intensity of large-scale cyclic movements of male players in handball. Kinesiology 2004;36(1):58-68.

30. Póvoas SC, Seabra AF, Ascensão AA, Magalhães J, Soares, JM, Rebelo AN. Physical and physiological demands of elite team handball. J Strength Cond Res 2012;26(12), 3365-3375.

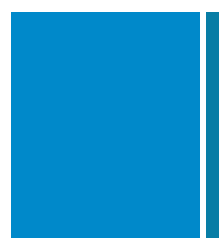

Corresponding author

David Mancha Triguero

Doctorando en Ciencias del Deporte

Grupo de Optimización del Entrenamiento y Rendimiento Deportivo (GOERD).

Facultad de Ciencias del Deporte, Universidad de Extremadura.

Avenida de la Universidad s/n. 10071, Cáceres, España.

Email:dmanchat@alumnos.unex.es 